\title{
The Pathobiological Basis for Thrombotic Complications in COVID-19: a Review of the Literature
}

\author{
Lara Hoteit ${ }^{1} \cdot$ Andrew-Paul Deeb $^{1} \cdot$ Elizabeth A. Andraska ${ }^{2} \cdot$ Christof Kaltenmeier $^{1} \cdot$ Hamza O. Yazdani $^{1}$. \\ Samer Tohme ${ }^{3} \cdot$ Matthew D. Neal ${ }^{1} \cdot$ Roberto I. Mota $^{1,4,5}$
}

Accepted: 10 November 2021 / Published online: 8 December 2021

( ) The Author(s), under exclusive licence to Springer Science+Business Media, LLC, part of Springer Nature 2021

\begin{abstract}
Purpose of Review COVID-19 has rapidly evolved into a global pandemic infecting over two hundred and forty-four million individuals to date. In addition to the respiratory sequelae and systemic infection that ensues, an alarming number of micro and macrovascular thrombotic complications have been observed. This review examines the current understanding of COVID19-associated thrombotic complications, potential mechanisms, and pathobiological basis for thromboses development.

Recent Findings The endothelium plays a major role in the process due to direct and indirect injury. The immune system also contributes to a pro-thrombotic environment with immune cell dysregulation leading to excessive formation of cytokines, also called cytokine storm, and an eventual promotion of a hypercoagulable environment, known as immunothrombosis. Additionally, neutrophils play an important role by forming neutrophil extracellular traps, which are shown to be pro-thrombotic and further enhanced in COVID-19 patients. A disruption of the fibrinolysis system has also been observed.

Summary Multiple pathways likely contribute synergistically to form a pro-thrombotic milieu. A better understanding of these factors and the complex interplay between them will lead to the improvement of diagnostic and therapeutic interventions.
\end{abstract}

Keywords COVID-19 Coronavirus $\cdot$ Thrombosis $\cdot$ VTE $\cdot$ Hypercoagulable $\cdot$ Immunothrombosis

Lara Hoteit and Andrew-Paul Deeb functioned as co-first authors for this publication.

Matthew D. Neal and Roberto I. Mota functioned as co-senior authors for this publication.

This article is part of the Topical Collection on Wound Healing and Tissue Repair

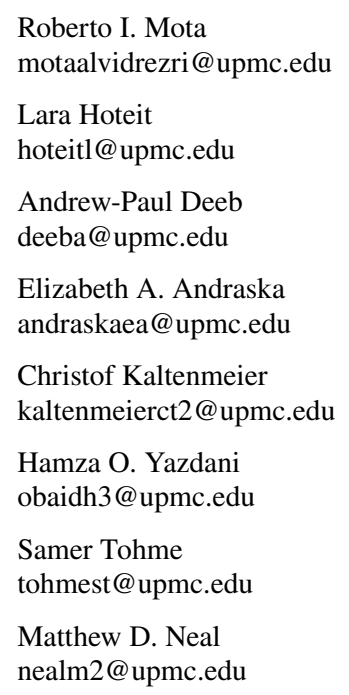

\section{Introduction}

COVID-19 is caused by severe acute respiratory syndrome coronavirus 2 (SARS-CoV-2) and infection ensues with variable presentation from asymptomatic carriage or mild upper

1 Division of Trauma and General Surgery, Department of Surgery, University of Pittsburgh Medical Center, Pittsburgh, PA 15213, USA

2 Division of Vascular Surgery, Department of Surgery, University of Pittsburgh Medical Center, Pittsburgh, PA 15213, USA

3 Division of Surgical Oncology, Department of Surgery, University of Pittsburgh Medical Center, Pittsburgh, PA 15213, USA

4 McGowan Institute for Regenerative Medicine, University of Pittsburgh, F1271.2 PUH, 200 Lothrop St, W939 Biomedical Science Tower, Pittsburgh, PA, 15213, USA

5 Vascular Medicine Institute, University of Pittsburgh, Pittsburgh, PA 15213, USA 
respiratory symptoms to severe symptoms with pneumonia, sepsis, multiple system organ failure, and death [1]. In addition, with time, a broad range of extra-pulmonary sequelae have become apparent. An alarming number of thrombotic complications have been observed, despite standard chemoprophylaxis [2-4]. The current incidence of thrombotic complications ranges from seven to greater than $40 \%$, with much higher estimates observed with severe disease and for patients requiring ICU admission [5-7]. Coagulation panels demonstrate worsened derangement with increased disease severity [2, 8]. Deep venous thrombosis (DVT) and pulmonary emboli (PE) are the most commonly reported thrombotic events that are associated with SARS-CoV-2 infection $[3,9,10]$. Additionally, arterial thrombosis, splenic and cerebral venous thrombosis [11], mesenteric ischemia [12], stroke [13], acro-ischemia [14], kidney microthrombi [15], renal replacement and extracorporeal membrane oxygenation (ECMO) circuitry clotting [16] among others are reported. These collective observations brought recognition to the need for early clinical suspicion for thrombosis with timely diagnostics and treatment, and the consideration of interval screening tests [17]. Prophylactic and therapeutic anticoagulation dosage and duration, with consideration for disease severity, remains an area of clinical uncertainty and active investigation $[18,19]$. Many of the anti-coagulation studies in COVID-19 focus on outcomes of respiratory failure and acute lung injury which are hypothesized to occur, at least in part, due to microvascular thrombosis. Ultimately, we need to better understand the pathobiology of coagulopathy and thrombosis associated with COVID-19 to optimize our management.

Hospitalized patients are at heightened risk for VTE due to multifactorial insults on Virchow's triad of hypercoagulability, endothelial damage, and immobility [20]. Intuitively, VTE rates are increased in critically ill patients with exacerbation of all these factors. The regular use of mechanical and chemical prophylaxis significantly reduced the incidence of VTE [21], yet the rates in COVID-19 patients far exceed what would be expected in comparatively similar risk patients [3, 21, 22]. This observation led to the myriad of evolving investigations to delineate the mechanisms of inflammation and molecular biology that contribute to the disproportionately high rate of thrombosis with COVID-19.

In addition to the high incidence of macrovascular VTE, multiple studies have reported a unique pattern of microvascular pulmonary vasculopathy, which some have termed pulmonary intravascular coagulation or dysregulated immunothrombosis, distinct on histopathologic assessment from other pulmonary infections [2, 23]. Nicolai and colleagues [23] conducted a histopathologic analysis of autopsy cases and reported immunothrombosis in multiple body systems consisting of neutrophils associated with platelets and fibrin deposition causing tissue damage, microvascular occlusion, and hypoxia. Another autopsy study compared the lungs of patients deceased from COVID-19 and those of influenza A [24]. COVID-19 patients demonstrated unique disruption of cell membranes, intracellular virus with severe endothelial injury, microvascular occlusion, and neovascularization [24].

Patients exhibit multiple biochemical derangements commonly observed in acute inflammation and several that are consistent with a hypercoagulable state. D-dimer, a fibrin degradation product, is most consistently elevated. It is an early but nonspecific abnormality observed in imbalanced coagulation pathways; it is elevated with microvascular or macrovascular thrombosis and a surrogate for thrombus burden with marked elevations associated with mortality in COVID-19 patients [25]. Interestingly, elevated D-dimer is also associated with bleeding complications, making the use of D-dimer as a predictor of thrombosis somewhat confounded [26]. Elevations are also reported in acute phase reactants fibrinogen, C-reactive protein, ferritin, factor VIII, and Von Willebrand factor. Some report a mild thrombocytopenia [23, 27]. Consumptive coagulopathy consistent with disseminated intravascular coagulation (DIC) has been described in severe late stages of disease, marked by prolonged prothrombin time, activated partial thromboplastin time, thrombocytopenia, and hyperfibrinolysis [8].

Coagulopathy associated with inflammation and viral infections was previously observed; however, the incidence with COVID-19 is striking and differs in proposed mechanisms from prior infectious agents [25]. This narrative review will delve into the theories underlying these unique observations and attempt to provide one coherent picture for the pathobiological basis of coagulopathy in COVID-19. However, one must be cognizant that our grasp of these mechanisms is rapidly evolving with the constant influx of data and publications. It is noteworthy that during this review we observed the retraction of several articles which suggests the need for refinement in the balance of peer-review processing with the need for critical and timesensitive knowledge dissemination [28]. This pandemic may have ushered in a new era of the peer-review process through the rise of open-access and pre-print articles in efforts to achieve early access to recommendations given the rising case number and mortalities. Thus, it is important to stay appraised of the literature and to validate new findings.

\section{Literature Search}

We reviewed articles retrieved from PubMed and Medline with the terms "COVID-19," "SARS CoV-2," "coagulopathy," and "thrombus" entered as keywords for our search. We included scientific publications from 1 December 2019 to October 24th, 2021. Articles were screened by their titles 
and abstract for inclusion. Reference lists of relevant studies were also screened to identify pertinent publications.

\section{Proposed Mechanisms of Hypercoagulability in COVID-19}

Multiple pathways lead to the creation of a favorable milieu for hypercoagulability in patients with COVID-19. These pathways include direct and indirect injury to the endothelium, a dysregulation in the immune response, and a disruption of the fibrinolytic pathway. These factors will be looked at individually; however, it is important to note that it is likely that these factors work synergistically as well.

\section{Endotheliopathy}

It is believed that an inciting point of coagulopathy associated with COVID-19 occurs via either direct or indirect damage of the endothelium by viral infection of endothelial cells and systemic inflammation [24, 29]. Damage to the endothelial cells exposes the subendothelial matrix, rich in collagen and tissue factor, thereby initiating the coagulation cascade [30] (Fig. 1). Endotheliopathy results in disruption of the glycocalyx with increased endothelial cell permeability which is implicated in fluid overload, coagulopathy, inflammation, and multiple system organ failure as well as platelet and neutrophil recruitment and thrombus formation [30-32].

Elevated levels of circulating biomarkers due to endotheliopathy were observed in hospitalized patients and those admitted to the ICU [33, 34]. These biomarkers included Von Willebrand factor (vWF), plasminogen activator inhibitor 1 (PAI-1), angiopoietin 2, follistatin, soluble thrombomodulin, and syndecan-1 [33-36]. It is well established that the extrinsic pathway of coagulation is activated with endothelial activation or damage with tissue factor expression [37], tipping the balance towards thrombosis. Endothelial damage may occur via direct or indirect pathways.

\section{Direct Endothelial Damage}

Evidence of endothelial entry by virions, via the ACE-2 receptor, is demonstrated by the presence of viral inclusion bodies within the endothelium [29]. This entry may lead to the direct activation and subsequent release of Von Willebrand factor from their Weibel-Palade bodies, prompting platelet binding and microthrombosis if not cleaved by ADAMTS13 [38]. Consistent with this proposed mechanism, COVID-19 patients often have significantly elevated vWF levels as reported in multiple studies, with several demonstrating a correlation of vWF with disease severity, thromboembolic events, and mortality [16, 27, 38]. SARS-CoV-2 can also directly induce vascular endotheliitis as shown by the aggregation of inflammatory leukocytes around the vascular endothelial cells [29].

\section{Environmental Stress on Endothelium}

SARS-CoV-2 infection leads to an increase in oxidative stress in endothelial cells causing them to become dysfunctional [39]. Reactive oxygen species stimulate the expression of tissue factor which prompts the activation of the extrinsic coagulation pathway and can inactivate protein C, an anticoagulant which functions to maintain the coagulation cascade in homeostatic balance [39]. Oxidative stress also leads to the formation of oxidized phospholipids which
Fig. 1 Schematic representation of the multiple pathways that lead to the activation of coagulation and thrombosis. Direct and indirect mechanisms of endothelial damage contribute to a disruption in the endothelium that would initiate the coagulation cascade. The inflammation caused by COVID-19, which leads to a cytokine storm, is also an important contributor. Other mechanisms are not shown in the figure above, including the role that fibrinolysis and antiphospholipid antibodies play. Created with BioRender

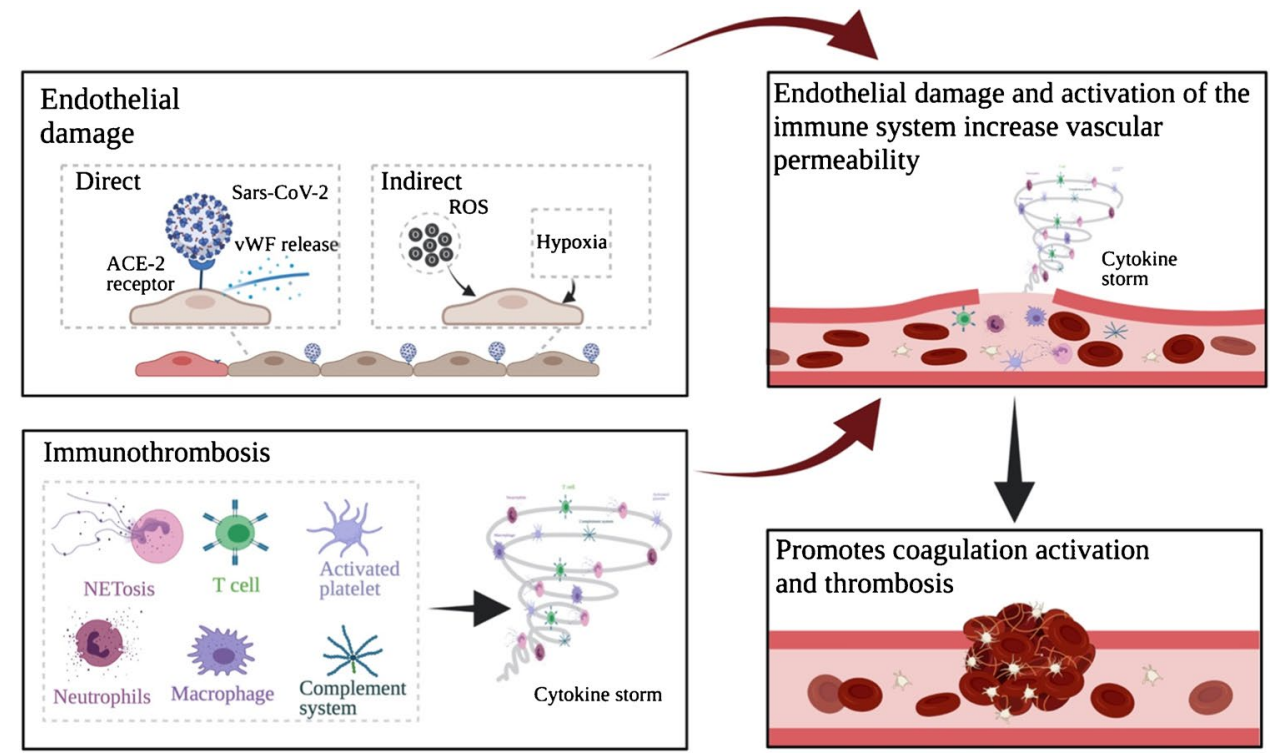


promotes the activation of monocyte-derived macrophages which may contribute to a cytokine storm, as well as membrane tissue factor expression, both of which predispose the patient to a heightened risk of thrombus formation. Oxidative phospholipids are also capable of inducing the expression of transcription factors that activate endothelial cells and lead to recruitment and binding of activated monocytes and neutrophils, as seen in other disease processes and contribute to a procoagulant milieu [40].

The hypoxia suffered by patients with moderate to severe COVID-19 infection also contributes to coagulopathy. Hypoxia-inducible transcription factors (HIF) are generated as a vascular compensatory response to decreased oxygen tension and, amidst the HIF targets, are pro-thrombotic factors including plasminogen activator inhibitor and others that regulate the pathway such as early growth response 1 (EGR1). Hypoxia also causes an upregulation of pro-inflammatory cytokines tumor necrosis factor $\alpha(\mathrm{TNF}-\alpha)$ and interleukin 1 (IL-1) which are indirectly linked to thrombosis [41].

\section{Platelet Role in Endotheliopathy}

Recent evidence points towards a role for platelets in endotheliopathy. Barrett et al. [42] demonstrated the presence of two main RNA transcripts, S100A8 and S100A9, expressed in platelets from COVID-19 patients that lead to the release of myeloid-related protein (MRP) 8/14. This was shown to activate endothelial cells and promote an inflammatory hypercoagulable phenotype.

\section{Immunomodulatory Effects of COVID-19}

Immunomodulation plays an integral role in the perturbation of coagulation homeostasis. The intricate relationship between the coagulation pathway and the immune system has been described and imbalances may lead to immunothrombosis $[23,43]$. This is a process involving the innate immune system, clotting factors, and platelets that function to fight and trap pathogens but also results in inflammation, tissue injury, fibrin deposition, vessel occlusion, and hypoxia [23]. Multiple key players contribute to a pro-inflammatory environment which in turn incites a hypercoagulable state and thrombosis: neutrophil and platelet recruitment, macrophage activation, complement activation, and T cell modulation (Fig. 1). Taken together, these processes enhance the production of cytokines and may, in certain patients, lead to a cytokine storm [44]. The aforementioned immune processes independently contribute to hypercoagulability as will be elaborated, but it is important to note that they are likely to function synergistically to favor thrombosis as well.

\section{Cytokine Storm}

Several studies report elevations in a specific profile of cytokines associated with severe disease, ICU admission, and adverse outcomes. In a study published early during the pandemic, Huang et al. [45] observed higher serum levels of interleukin (IL)-2, IL-6 IL-7, IL-10, granulocyte colony stimulating factor (G-CSF), interferon (IFN)- $\gamma$, inducible protein 10 (IP-10), monocyte chemoattractant protein 1 (MCP-1), macrophage inflammatory protein 1A (MIP-1A), and TNF- $\alpha$ in patients admitted to the ICU as compared to non-ICU patients. In a prospective cohort study, elevations in 14 cytokines were observed with a subset including IP-10, MCP-3, and IL-1RA specifically associated with disease progression and correlated with the $\mathrm{PaO}_{2} / \mathrm{FiO}$ ratio and a high Murray score. This score is utilized in the evaluation of acute respiratory distress syndrome (ARDS) and is helpful for patient selection for extracorporeal membrane oxygenation [46]. Many others demonstrated an increase in pro-inflammatory cytokines which often peak 4 to 6 days after disease onset and correlate with progressive disease severity and need for intensive care [47, 48]. This hyperactive inflammatory response potentiates a vicious cycle of unchecked inflammation and excessive cytokine release creating the so termed cytokine storm with dysregulation of the immune response which may preclude effective viral clearance and predispose to hypercoagulability $[49,50]$.

It is important to note the modulatory role of pro-inflammatory cytokines in the coagulation pathway. IL-2 has been shown to stimulate endothelial PAI-1 release in vitro offering a potential mechanism of fibrinolysis inhibition [49, 50]. Others report potential for hypercoagulation through impairment of endothelial cells [50, 51]. IL-2 also promotes the differentiation of $\mathrm{T}$ cells which produce IFN- $\gamma$ which is itself implicated in several procoagulant mechanisms. IFN- $\gamma$ promotes thrombus formation by increasing platelet adhesion and activation of monocytic cells [50, 52], which in turn increases the expression of tissue factor [50, 53]. It also mediates monocyte recruitment to blood vessels leading to vascular endothelial and smooth muscle cell dysfunction [50, 54]. Additionally, IFN- $\gamma$ contributes to the formation of pro-thrombotic neutrophil extracellular traps (NETs) and leads to downregulation of vascular endothelial growth factor (VEGF) and matrix metalloproteinase 9 (MMP-9) expression in macrophages which impedes thrombus resolution; both pathways are implicated in pro-thrombotic states [50]. IL-6 increases tissue factor expression in endothelial cells and monocytes. Animal data also suggests a modulation of circulating clotting factors with increased fibrinogen and vWF following increases in IL-6. There is consensus that IL-6 may lead to endothelial dysfunction associated with hypercoagulability $[50,55,56]$. A postulated mechanism is through upregulation of the NF- $\mathrm{KB}$ signaling 
pathway with apoptosis of endothelial cells [30]. TNF- $\alpha$, a pro-inflammatory cytokine, promotes thrombosis through activation of the complement system, through the production of tissue factor, and disruption of protein $\mathrm{C}$ receptor and thrombomodulin $[57,58]$.

\section{Neutrophils and Platelets}

Neutrophils are fundamental to the development of immunothrombosis. To combat infection, neutrophils release leukotrienes, reactive oxygen species, and along with activated platelets, form NETs that are induced by cytokines. NETs are extracellular web-like structures composed of nuclear chromatin, associated proteins, and bactericidal enzymes such as elastase and myeloperoxidase (MPO) [59]. These structures also propagate inflammation in COVID-19 and are implicated in microvascular thrombosis which is a hallmark characteristic of severe infection, hypercoagulability, and multiple system organ failure $[23,60]$. NETs facilitate adhesion and activation of platelets, capture red blood cells, and may drive arterial, venous, and microvascular thrombosis [61]. Prior work demonstrated higher NET levels in hospitalized COVID-19 patients as compared to healthy controls [62] as well as elevated levels in patients with COVID-19 and concomitant thrombosis [63]. Markers of NETs include cell-free DNA, MPO-DNA complexes, and citrullinated histone H3. Cell-free DNA is shown to activate the coagulation pathway [64] and oxidant enzymes and histones are cytotoxic, contribute to the pro-inflammatory milieu and to vessel wall injury [60]. Gould et al. [64] showed that dismantling of the NET scaffold could increase histone-mediated, platelet-dependent thrombin generation. Neutrophils are also capable of releasing NETs that express tissue factor when activated by inflammatory mediators leading to a direct activation of the extrinsic pathway of coagulation [65]. It is also postulated that some patients possess pathogenic host factors that allow the virus to evade the innate immune response leading to an impairment in NETs and circulating DNA function. This results in chronic NET auto-stimulation and potentially to the previously described cytokine storm and prothrombotic state [61]. The relationship between high circulating NETs and thrombus formation is under further study in septicemia models wherein intravascular NETs form occlusive microthrombi contributing to multiple organ injury [66].

Prior work also suggests a correlation between the severity of illness and the degree of neutrophil response and subsequent risk of thrombosis. In a case-control study, Zuo et al. [63] demonstrated that patients in severe respiratory failure requiring intubation had the greatest NET elevation. Others observed a correlation between NET level and D-dimer, increasing speculation of the interplay between neutrophils, platelets, and endothelial cells in the model of thromboinflammation [63, 64, 67]. COVID-19 patients with thrombotic events are shown to have elevated NETs, D-dimer, and peak activated platelet count as compared to those without evidence of thrombosis [63].

An analysis of autopsies from fatal cases of severe COVID-19 demonstrated an alteration in neutrophil phenotype as detected by flow cytometry to favor activated neutrophils, defined as neutrophils with markers for CD11b, CD62L, CD63, and CD15, particularly in severe cases that required mechanical ventilation [23]. Quantitative and qualitative changes in neutrophils and platelets correlated with disease severity and demonstrated upregulation of activated platelets and platelet-neutrophil aggregates leading to NET formation and fibrin deposition. This work highlights the link between dysregulated platelets, neutrophil activation, and NETosis with subsequent microvascular occlusion. Histopathologic analysis showed microvascular thromboses in cardiac, pulmonary, and renal vasculature of patients with antemortem myocardial insult, respiratory and renal failure. These findings, importantly, were absent in healthy control tissue. The authors also note that even in the absence of macrovascular thrombosis, fibrin and D-dimer is elevated in severe disease which may be a result of profound microvascular immunothrombosis underpinning the multiple system organ failure in critical patients [23].

Platelets are an important component of coagulation and are substantially impacted by the immune system dysregulation that contributes to immunothrombosis. Thrombocytopenia has been observed in COVID-19; however, increased levels of activation and structural abnormalities contribute to increased thrombogenicity. As discussed, activated platelets trigger the deployment of NETs [61]. They also function to recruit and assist with diapedesis of leukocytes [68, 69], the secretion of complement [70], and demonstrate increased neutrophil aggregation. Increased mean platelet volume (enhanced fibrinogen binding) as well as greater tissue factor expression has been shown $[25,71]$. Each of these functions contributes to inflammation and, via direct and indirect mechanisms, potentiates a procoagulant state.

Zhang et al. [72] studied platelets from COVID-19 patients and monitored ACE2 expression. They found that SARS-CoV-2 virus and the spike protein directly enhances platelet activation and aggregation, granule secretion, and platelet spreading on fibrinogen and collagen. Markers of platelet activation such as $\mathrm{P}$-selectin and soluble CD40L are increased in COVID-19 despite normal or mildly reduced platelet count $[33,73]$. In addition, the mitogen-associated protein kinase (MAPK) pathway and thromboxane production are upregulated proving to be important mediators of the virus on platelet activation as compared to control patients [74]. 


\section{Monocytes and Macrophages}

Monocytes and macrophages also play an important role in excessive inflammation of COVID-19. Although the number of monocytes was unchanged across healthy controls and COVID-19 patients [75], phenotypic alterations in macrophages were observed and accentuated in ICU patients. These cells were larger and portrayed markers specific to polarized macrophages such as CD80 for M1 proinflammatory macrophages and CD206 for M2 anti-inflammatory macrophages [75]. These monocytes demonstrate an increased proclivity to bind platelets in a complex that may induce immunothrombosis [2]. Furthermore, the expression levels of M1 specific cytokines IL-6 and TNF- $\alpha$ were higher in SARS-CoV-2 infection [2, 75]. Although a difference in expression levels of M2 specific cytokine IL-10 was seen between patients and controls, it was not statistically significant. These findings suggest that peripheral monocytes and differentiated macrophages of COVID-19 patients play a key role in hyper-stimulatory cytokine release [75]. Monocytes are further activated by chemo-attractants secreted by alveolar cells and macrophages after direct viral infection [40]. Natural killer cells and T cells [76] also promote the recruitment of monocytes through the production of GMCSF, TNF- $\alpha$ and IFN- $\gamma$ among other cytokines $[40,77]$.

These inflammatory cells are also shown to induce gene expression for proteins such as fibrinogen, serine protease inhibitors, tissue factor, prothrombin, prothrombinase, and factor $\mathrm{X}$, in in vitro models $[48,78]$. Monocytes can also be induced to express tissue factor via TNF- $\alpha$ [48]; all of which may contribute to imbalances in the coagulation cascade favoring thrombosis. Other proposed mechanisms of macrophage-mediated hypercoagulability include macrophage-derived reactive oxygen species which inactivates endothelial nitrous oxide and potentiates endothelial dysfunction. Proteins such as macrophage stimulating protein 1 (MST1) also contribute to endothelial cell death, and both mechanisms may thereby incite a pro-thrombotic state [30].

\section{Complement Cascade}

The complement system acts directly and indirectly to promote thrombosis and multiple studies reveal a highly activated complement cascade across multiple COVID-19 patient tissues upon biopsy and autopsy [79, 80]. Complement assists in the recruitment and activation of leukocytes leading to the amplification of proinflammatory cytokines [48]. It also induces microvascular injury and immunothrombosis through terminal components of complement activation such as C5b-9, C4d, and mannose-binding lectin associated serine protease (MASP) [48]. Mannose-binding lectin has been strongly correlated with increased D-dimer levels [81]. C5a can induce the expression of tissue factor on endothelial cells and neutrophils setting off the extrinsic clotting pathway. It is also shown to upregulate PAI-1, thereby inhibiting fibrinolysis [82]. Previous animal sepsis model studies were used to study the interface between complement and coagulation. Results showed a decrease in inflammation-induced coagulopathy with inhibition of complement pathways $[48,83]$.

\section{T Cell Dysregulation}

There is dysregulation in the T cell response to COVID-19 that leads to ineffective viral clearance and to over activation of the inflammatory response. In a retrospective study, Wan et al. [84] showed that COVID-19 patients with severe disease have a lower level of CD4 + and CD $8+T$ cells. This potentially contributes to ineffective viral clearance. Zhou et al. [77] demonstrated increased activation of CD4+ and $\mathrm{CD} 8+\mathrm{T}$ cells present in infected as compared to healthy controls. The authors also show COVID-19 patients secreted greater pro-inflammatory cytokines and that aberrant $\mathrm{Th} 1$ and Th17 responses play a role in perpetrating hyperstimulation of the immune system, cytokine storm, endothelial damage, and coagulopathy [85, 86]. Diao et al. [87] demonstrated that prolonged infection leads to T cell exhaustion, measured by the expression of PD- 1 and Tim- 3 on cell surfaces, and therefore a decrease in function of $\mathrm{T}$ cells.

\section{Impairment of Fibrinolysis}

It is believed that fibrinolysis impairment also contributes to hypercoagulability [70]. Multiple reports show an increase in PAI-1 in COVID-19, especially ICU patients. This diminishes fibrin degradation associated with physiologic thrombus resolution [33]. Endothelial cells are the primary source of production of PAI-1, and endotheliopathy is well established in COVID-19, implicating this aberrancy as a likely contributory mechanism in the coagulation cascade imbalances $[33,70]$. In a single-center cohort of 40 ICU patients admitted for COVID-19, Kruse et al. [88] studied fibrinolysis with viscoelastic rotational thromboelastometry (ROTEM). They found that patients with COVID-19, especially those that suffered a thromboembolic event, demonstrated hypofibrinolysis [88].

\section{Antiphospholipid Antibodies}

Several reports have documented the presence of antiphospholipid antibodies in critically ill COVID-19 patients. This phenomenon was previously observed with other viruses in which antibody titers were generally found to be transient; however, some patients developed the clinical antiphospholipid antibody syndrome $[25,89,90]$. In one small study of COVID-19, 91\% of patients with prolonged aPTT were 
found to have lupus anticoagulant compared to $26 \%$ of a historical control with elevated aPTT but no COVID-19 [91]. In another study, all patients with symptomatic thrombotic events had positive antiphospholipid antibodies [92]. It is noteworthy that both studies were derived from small sample sizes which indicates the need for ongoing investigation.

Zuo et al. [93] looked at different types of antiphospholipid antibodies in a cohort of 172 hospitalized patients with COVID-19 and found that $52 \%$ of the patients tested positive for at least one type of antibody. The majority of positive serum samples were associated with 3 types of autoantibodies: aPS/PT IgG, aCL IgM, and aPS/PT IgM. The presence of these autoantibodies was correlated with multiple clinical parameters such as D-dimer, fraction of inspired oxygen, platelet counts, and absolute neutrophil counts as well as markers for neutrophil activation such as calprotectin and markers for NET formation such as myeloperoxidase-DNA complexes. The relationship between NET formation and the autoantibodies was further investigated by adding purified IgG fraction from the serum of COVID-19 patients to neutrophils isolated from healthy individuals resulting in an increase in the release of NETs. The group also investigated the potential role of these $\operatorname{IgG}$ fractions isolated from COVID-19 patient serum in the acceleration of thrombosis through a mice thrombosis model. A statistically significant increase in thrombus extension and accretion as well as circulating NET remnants was observed after injecting the mice with the IgG fractions, leading to the hypothesis that the IgG fractions are able to accelerate thrombosis in vivo [93].

\section{An Update in Clinical Trials}

In an attempt to find a solution for the increase in thrombotic events, multiple groups have published findings from clinical trials evaluating patients with COVID-19. Randomized controlled trials done in the outpatient setting on patients with symptomatic COVID-19 infection did not show a reduction in rate of a composite clinical outcome (which includes allcause mortality, symptomatic venous or arterial thromboembolism, myocardial infarction, stroke, or hospitalization for cardiovascular or pulmonary causes) when treated with aspirin or apixaban compared to placebo [94]. Studies done on moderately ill patients with COVID-19 admitted to hospital wards showed a decrease in the odds of death at 28 days with therapeutic heparin in comparison with prophylactic heparin [95]. This study showed no difference in their primary outcome, a composite of death, invasive mechanical ventilation, non-invasive mechanical ventilation, or admission to ICU [95]. In a randomized controlled trial evaluating hospitalized but non-critically ill COVID-19 patients, those treated with therapeutic dose of heparin were shown to have an increased probability of survival to hospital discharge as well as a decreased probability of using organ support machinery compared to patients receiving usual care thromboprophylaxis [96]. High-risk hospitalized patients with COVID-19 seemed to have a decreased risk for major thromboembolism and death when treated with therapeutic dose of low molecular weight heparin as compared to institutional standard heparin thromboprophylaxis. Other trials looked at critically ill patients with severe COVID-19. One of those studies showed no significant difference in their primary outcomes of venous or arterial thrombosis, treatment with ECMO, or mortality within 30 days when comparing intermediate dose vs standard dose prophylactic anticoagulation with enoxaparin [97]. The REMAP-CAP, ACTIV-4a, and ATTACC investigators also looked at critically ill patients with severe COVID-19. In their study, therapeutic dose of anticoagulation with heparin compared to usual care pharmacologic thromboprophylaxis did not result in an increase in survival to hospital discharge or a decrease in reliance on organ support [98].

\section{Conclusions}

Our understanding of the pathobiology of thrombotic complications of COVID-19 is evolving rapidly. Micro and macrovascular thrombosis drives outcomes in COVID-19 and microvascular thrombosis contributes to multiple system organ failure and mortality. A firm grasp of the biological underpinnings of this disease and the thrombotic complications sets the basis for clinical trials that evaluate new therapeutic interventions to reduce the burden of thrombosis due to COVID-19. Those include, but are not limited to, the use of immune modulators and the evaluation of threshold and dosing for prophylactic, intermediate, or full-dose anticoagulation. Our review highlights the important underlying basis for the COVID-19 hypercoagulable milieu while also emphasizing that it is not just macrovascular thrombosis that impacts patient outcomes, but microvascular. Although some mechanisms are incompletely elucidated, the hypercoagulable milieu of SARS-CoV-2 infection is certain. A combination of the processes discussed herein contribute but are likely not limited to a loss of endothelial integrity, dysregulated immune cell responses, and a pro-coagulant tipping of the balance of the coagulation-fibrinolytic pathways. We acknowledge limitations to this review, primarily that the data is changing rapidly particularly in regard to potential therapeutics that follow our evolving understanding of mechanistic targets.

Funding 1R35GM119526-01 to MDN. 
Availability of Data and Material Not applicable.

Code Availability Not applicable.

\section{Declarations}

Conflict of Interest MDN has the following financial relationships to disclose: Consultant, External Scientific Advisor for Anticoagulation Science for Janssen Pharmaceuticals (Johnson \& Johnson), research funding from Haemonetics and Instrument Laboratories, Scientific Advisory Board of Haima Therapeutics, Trauma Advisory Board, CSL Behring, and US Patent 9,072,760 TLR4 inhibitors for the treatment of human infectious and inflammatory disorders (issued to Neal, Wipf, Hackam, Sodhi).

The additional authors declare that no significant conflicts of interest exist.

Human and Animal Rights and Informed Consent This article does not contain any studies with human or animal subjects performed by any of the authors.

\section{References}

1. Wang C, Horby PW, Hayden FG, Gao GF. A novel coronavirus outbreak of global health concern. Lancet. 2020;395(10223):4703. https://doi.org/10.1016/S0140-6736(20)30185-9.

2. Obi AT, Barnes GD, Napolitano LM, Henke PK, Wakefield TW. Venous thrombosis epidemiology, pathophysiology, and anticoagulant therapies and trials in severe acute respiratory syndrome coronavirus 2 infection. J Vasc Surg Venous Lymphat Disord. 2021;9(1):23-35. https://doi.org/10.1016/j.jvsv.2020.08.030.

3. Middeldorp S, Coppens M, van Haaps TF, Foppen M, Vlaar AP, Muller MCA, et al. Incidence of venous thromboembolism in hospitalized patients with COVID-19. J Thromb Haemost. 2020;18(8):1995-2002. https://doi.org/10.1111/jth.14888.

4. Klok FA, Kruip M, van der Meer NJM, Arbous MS, Gommers D, Kant KM, et al. Incidence of thrombotic complications in critically ill ICU patients with COVID-19. Thromb Res. 2020;191:145-7. https://doi.org/10.1016/j.thromres.2020.04.013.

5. Kunutsor SK, Laukkanen JA. Incidence of venous and arterial thromboembolic complications in COVID-19: a systematic review and meta-analysis. Thromb Res. 2020;196:27-30. https://doi.org/ 10.1016/j.thromres.2020.08.022.

6. Al-Ani F, Chehade S, Lazo-Langner A. Thrombosis risk associated with COVID-19 infection. A scoping review Thrombosis Research. 2020;192:152-60. https://doi.org/10.1016/j.thromres. 2020.05.039.

7. Bilaloglu S, Aphinyanaphongs $\mathrm{Y}$, Jones S, Iturrate E, Hochman J, Berger JS. Thrombosis in hospitalized patients with COVID-19 in a New York City health system. JAMA. 2020;324(8):799-801. https://doi.org/10.1001/jama.2020.13372.

8. Thachil J, Cushman M, Srivastava A. A proposal for staging COVID-19 coagulopathy. Res Pract Thromb Haemost. 2020;4(5):731-6. https://doi.org/10.1002/rth2.12372.

9. Llitjos JF, Leclerc M, Chochois C, Monsallier JM, Ramakers M, Auvray M, et al. High incidence of venous thromboembolic events in anticoagulated severe COVID-19 patients. J Thromb Haemost. 2020;18(7):1743-6. https://doi.org/10.1111/jth.14869.

10. Wichmann D, Sperhake JP, Lutgehetmann M, Steurer S, Edler C, Heinemann A, et al. Autopsy findings and venous thromboembolism in patients with COVID-19: a prospective cohort study. Ann Intern Med. 2020;173(4):268-77. https://doi.org/10. 7326/M20-2003.

11. Cavalcanti DD, Raz E, Shapiro M, Dehkharghani S, Yaghi S, Lillemoe K, et al. Cerebral venous thrombosis associated with COVID-19. AJNR Am J Neuroradiol. 2020;41(8):1370-6. https://doi.org/10.3174/ajnr.A6644.

12. Cheung S, Quiwa JC, Pillai A, Onwu C, Tharayil ZJ, Gupta R. Superior mesenteric artery thrombosis and acute intestinal ischemia as a consequence of COVID-19 infection. Am J Case Rep. 2020;21: e925753. https://doi.org/10.12659/AJCR.925753.

13. Szegedi I, Orban-Kalmandi R, Csiba L, Bagoly Z. Stroke as a potential complication of COVID-19-associated coagulopathy: a narrative and systematic review of the literature. J Clin Med. 2020;9:10. https://doi.org/10.3390/jcm9103137.

14. Alonso MN, Mata-Forte T, García-León N, Vullo PA, RamirezOlivencia G, Estébanez M, et al. Incidence, characteristics, laboratory findings and outcomes in acro-ischemia in COVID-19 patients. Vasc Health Risk Manag. 2020;16:467-78. https://doi. org/10.2147/vhrm.S276530.

15. Philipponnet C, Aniort J, Chabrot P, Souweine B, Heng AE. Renal artery thrombosis induced by COVID-19. Clin Kidney J. 2020;13(4):713. https://doi.org/10.1093/ckj/sfaa141.

16. Helms J, Tacquard C, Severac F, Leonard-Lorant I, Ohana M, Delabranche X, et al. High risk of thrombosis in patients with severe SARS-CoV-2 infection: a multicenter prospective cohort study. Intensive Care Med. 2020;46(6):1089-98. https://doi.org/ 10.1007/s00134-020-06062-x.

17. Hamade A, Jambert L, Tousch J, Talbot M, Dervieux B, Nazer TE, et al. Systematic duplex ultrasound screening in conventional units for COVID-19 patients with follow-up of 5 days. J Vasc Surg Venous Lymphat Disord. 2020. https://doi.org/10. 1016/j.jvsv.2020.11.019.

18. Anti-thrombotics for adults hospitalized with COVID-19 (ACTIV-4). https://ClinicalTrials.gov/show/NCT04505774.

19. Zarychanski R. Therapeutic anticoagulation in critically ill patients with Covid-19 - preliminary report. medRxiv. 2021;2021(03):10.21252749. https://doi.org/10.1101/2021.03. 10.21252749 .

20. Blann AD, Lip GY. Virchow's triad revisited: the importance of soluble coagulation factors, the endothelium, and platelets. Thromb Res. 2001;101(4):321-7. https://doi.org/10.1016/ s0049-3848(00)00419-9.

21. Bikdeli B, Madhavan MV, Jimenez D, Chuich T, Dreyfus I, Driggin E, et al. COVID-19 and thrombotic or thromboembolic disease: implications for prevention, antithrombotic therapy, and follow-up: JACC state-of-the-art review. J Am Coll Cardiol. 2020;75(23):2950-73. https://doi.org/10.1016/j.jacc.2020.04. 031.

22. Poissy J, Goutay J, Caplan M, Parmentier E, Duburcq T, Lassalle F, et al. Pulmonary embolism in patients with COVID-19: awareness of an increased prevalence. Circulation. 2020;142(2):184-6. https://doi.org/10.1161/circulationaha.120.047430.

23. Nicolai L, Leunig A, Brambs S, Kaiser R, Weinberger T, Weigand $\mathrm{M}$, et al. Immunothrombotic dysregulation in COVID-19 pneumonia is associated with respiratory failure and coagulopathy. Circulation. 2020;142(12):1176-89. https://doi.org/10.1161/ CIRCULATIONAHA.120.048488.

24. Ackermann M, Verleden SE, Kuehnel M, Haverich A, Welte T, Laenger F, et al. Pulmonary vascular endothelialitis, thrombosis, and angiogenesis in Covid-19. N Engl J Med. 2020;383(2):120-8. https://doi.org/10.1056/NEJMoa2015432.

25. Kamel MH, Yin W, Zavaro C, Francis JM, Chitalia VC. Hyperthrombotic milieu in COVID-19 patients. Cells. 2020;9(11):2392. https://doi.org/10.3390/cells9112392.

26. Al-Samkari H, Karp Leaf RS, Dzik WH, Carlson JCT, Fogerty AE, Waheed A, et al. COVID-19 and coagulation: bleeding and 
thrombotic manifestations of SARS-CoV-2 infection. Blood. 2020;136(4):489-500. https://doi.org/10.1182/blood.2020006520.

27. Panigada M, Bottino N, Tagliabue P, Grasselli G, Novembrino C, Chantarangkul V, et al. Hypercoagulability of COVID-19 patients in intensive care unit: a report of thromboelastography findings and other parameters of hemostasis. J Thromb Haemost. 2020;18(7):1738-42. https://doi.org/10.1111/jth.14850.

28. Boschiero MN, Carvalho TA, Marson FAL. Retraction in the era of COVID-19 and its influence on evidence-based medicine: is science in jeopardy? Pulmonology. 2021;27(2):97-106. https:// doi.org/10.1016/j.pulmoe.2020.10.011.

29. Varga Z, Flammer AJ, Steiger P, Haberecker M, Andermatt R, Zinkernagel AS, et al. Endothelial cell infection and endotheliitis in COVID-19. Lancet. 2020;395(10234):1417-8. https://doi.org/ 10.1016/S0140-6736(20)30937-5.

30. Maccio A, Madeddu C, Caocci G, La Nasa G. Multifactorial pathogenesis of COVID-19-related coagulopathy: can defibrotide have a role in the early phases of coagulation disorders? J Thromb Haemost. 2020;18(11):3106-8. https://doi.org/10.1111/jth.15021.

31. Milford EM, Reade MC. Resuscitation fluid choices to preserve the endothelial glycocalyx. Crit Care. 2019;23(1):77. https://doi. org/10.1186/s13054-019-2369-x

32. Haywood-Watson RJ, Holcomb JB, Gonzalez EA, Peng Z, Pati S, Park PW, et al. Modulation of syndecan-1 shedding after hemorrhagic shock and resuscitation. PLoS ONE. 2011;6(8): e23530. https://doi.org/10.1371/journal.pone.0023530.

33. Goshua G, Pine AB, Meizlish ML, Chang CH, Zhang H, Bahel $\mathrm{P}$, et al. Endotheliopathy in COVID-19-associated coagulopathy: evidence from a single-centre, cross-sectional study. Lancet Haematol. 2020;7(8):e575-82. https://doi.org/10.1016/S23523026(20)30216-7.

34. Meizlish ML, Pine AB, Goshua G, Chang CH, Zhang H, Bishai $\mathrm{J}$, et al. Circulating markers of angiogenesis and endotheliopathy in COVID-19. medRxiv. 2020;10:2045894020966547. https://doi. org/10.1101/2020.06.29.20140376.

35. Fraser DD, Patterson EK, Slessarev M, Gill SE, Martin C, Daley $\mathrm{M}$, et al. Endothelial injury and glycocalyx degradation in critically ill coronavirus disease 2019 patients: implications for microvascular platelet aggregation. Crit Care Explor. 2020;2(9): e0194. https://doi.org/10.1097/CCE.0000000000000194.

36. Yamaoka-Tojo M. Vascular endothelial glycocalyx damage in COVID-19. Int J Mol Sci. 2020;21(24):9712. https://doi.org/10. 3390/ijms21249712.

37. Mackman N, Tilley RE, Key NS. Role of the extrinsic pathway of blood coagulation in hemostasis and thrombosis. Arterioscler Thromb Vasc Biol. 2007;27(8):1687-93. https://doi.org/10.1161/ ATVBAHA.107.141911

38. Wool GD, Miller JL. The impact of COVID-19 disease on platelets and coagulation. Pathobiology. 2021;88(1):15-27. https://doi. org/10.1159/000512007.

39. Panfoli I. Potential role of endothelial cell surface ectopic redox complexes in COVID-19 disease pathogenesis. Clin Med (Lond). 2020;20(5):e146-7. https://doi.org/10.7861/clinmed.2020-0252.

40. Merad M, Martin JC. Pathological inflammation in patients with COVID-19: a key role for monocytes and macrophages. Nat Rev Immunol. 2020;20(6):355-62. https://doi.org/10.1038/ s41577-020-0331-4.

41. Gupta N, Zhao YY, Evans CE. The stimulation of thrombosis by hypoxia. Thromb Res. 2019;181:77-83. https://doi.org/10.1016/j. thromres.2019.07.013.

42. Barrett TJ, Cornwell M, Myndzar K, Rolling CC, Xia Y, Drenkova $\mathrm{K}$, et al. Platelets amplify endotheliopathy in COVID-19. Sci Adv. 2021;7(37):eabh2434. https://doi.org/10.1126/sciadv.abh2434.

43. Engelmann B, Massberg S. Thrombosis as an intravascular effector of innate immunity. Nat Rev Immunol. 2013;13(1):34-45. https://doi.org/10.1038/nri3345.
44. Blanco-Melo D, Nilsson-Payant BE, Liu WC, Uhl S, Hoagland D, Moller R, et al. Imbalanced host response to SARS-CoV-2 drives development of COVID-19. Cell. 2020;181(5):1036-45 e9. https:// doi.org/10.1016/j.cell.2020.04.026.

45. Huang C, Wang Y, Li X, Ren L, Zhao J, Hu Y, et al. Clinical features of patients infected with 2019 novel coronavirus in Wuhan. China Lancet. 2020;395(10223):497-506. https://doi.org/10.1016/ S0140-6736(20)30183-5.

46. Yang Y, Shen C, Li J, Yuan J, Wei J, Huang F, et al. Plasma IP-10 and MCP-3 levels are highly associated with disease severity and predict the progression of COVID-19. Journal of Allergy and Clinical Immunology. 2020;146(1):119-27.e4. https://doi.org/ 10.1016/j.jaci.2020.04.027.

47. Liu J, Li S, Liu J, Liang B, Wang X, Wang H, et al. Longitudinal characteristics of lymphocyte responses and cytokine profiles in the peripheral blood of SARS-CoV-2 infected patients. EBioMedicine. 2020;55: 102763. https://doi.org/10.1016/j.ebiom.2020. 102763.

48. Hanff TC, Mohareb AM, Giri J, Cohen JB, Chirinos JA. Thrombosis in COVID-19. Am J Hematol. 2020;95(12):1578-89. https:// doi.org/10.1002/ajh.25982.

49. Takahashi K, Uwabe Y, Sawasaki Y, Kiguchi T, Nakamura H, Kashiwabara K, et al. Increased secretion of urokinase-type plasminogen activator by human lung microvascular endothelial cells. Am J Physiol. 1998;275(1):L47-54. https://doi.org/10.1152/ajplu ng.1998.275.1.L47.

50. Du F, Liu B, Zhang S. COVID-19: the role of excessive cytokine release and potential ACE2 down-regulation in promoting hypercoagulable state associated with severe illness. J Thromb Thrombolysis. 2021;51(2):313-29. https://doi.org/10.1007/ s11239-020-02224-2.

51. Baars JW, de Boer JP, Wagstaff J, Roem D, Eerenberg-Belmer AJ, Nauta J, et al. Interleukin-2 induces activation of coagulation and fibrinolysis: resemblance to the changes seen during experimental endotoxaemia. Br J Haematol. 1992;82(2):295-301. https://doi. org/10.1111/j.1365-2141.1992.tb06421.x.

52. Todoroki N, Watanabe Y, Akaike T, Katagiri Y, Tanoue K, Yamazaki H, et al. Enhancement by IL-1 beta and IFN-gamma of platelet activation: adhesion to leukocytes via GMP-140/ PADGEM protein (CD62). Biochem Biophys Res Commun. 1991;179(2):756-61. https://doi.org/10.1016/0006-291x(91) 91881-c.

53. Del Prete G, De Carli M, Lammel R, D’Elios M, Daniel K, Giusti $\mathrm{B}$, et al. Th1 and Th2 T-helper cells exert opposite regulatory effects on procoagulant activity and tissue factor production by human monocytes. Blood. 1995;86(1):250-7. https://doi.org/10. 1182/blood.V86.1.250.bloodjournal861250.

54. De Caterina R, Libby P, Peng HB, Thannickal VJ, Rajavashisth TB, Gimbrone MA Jr, et al. Nitric oxide decreases cytokineinduced endothelial activation. Nitric oxide selectively reduces endothelial expression of adhesion molecules and proinflammatory cytokines. J Clin Invest. 1995;96(1):60-8. https://doi.org/10. 1172/JCI118074.

55. Gao H, Zhang Q, Chen J, Cooper DKC, Hara H, Chen P, et al Porcine IL-6, IL- $1 \beta$, and TNF- $\alpha$ regulate the expression of proinflammatory-related genes and tissue factor in human umbilical vein endothelial cells. Xenotransplantation. 2018;25(5): e12408. https://doi.org/10.1111/xen.12408.

56. Neumann FJ, Ott I, Marx N, Luther T, Kenngott S, Gawaz M, et al. Effect of human recombinant interleukin- 6 and interleukin- 8 on monocyte procoagulant activity. Arterioscler Thromb Vasc Biol. 1997;17(12):3399-405. https://doi.org/10.1161/01.atv.17.12. 3399.

57. Saha P, Smith A. TNF-alpha (tumor necrosis factor-alpha). Arterioscler Thromb Vasc Biol. 2018;38(11):2542-3. https://doi.org/ 10.1161/ATVBAHA.118.311660. 
58. Poredos P, Jezovnik MK. In patients with idiopathic venous thrombosis, interleukin-10 is decreased and related to endothelial dysfunction. Heart Vessels. 2011;26(6):596-602. https://doi.org/ 10.1007/s00380-010-0111-3.

59. Brinkmann V, Reichard U, Goosmann C, Fauler B, Uhlemann Y, Weiss DS, et al. Neutrophil extracellular traps kill bacteria. Science. 2004;303(5663):1532-5. https://doi.org/10.1126/scien ce. 1092385.

60. Zuo Y, Zuo M, Yalavarthi S, Gockman K, Madison JA, Shi H, et al. Neutrophil extracellular traps and thrombosis in COVID-19. medRxiv. 2020;5(2):446-53. https://doi.org/10.1101/2020.04.30. 20086736.

61. Thierry AR, Roch B. Neutrophil extracellular traps and by-products play a key role in COVID-19: pathogenesis, risk factors, and therapy. J Clin Med. 2020;9(9):2942. https://doi.org/10.3390/ jcm9092942.

62. Zuo Y, Yalavarthi S, Shi H, Gockman K, Zuo M, Madison JA, et al. Neutrophil extracellular traps in COVID-19. JCI Insight. 2020;5(11):e138999. https://doi.org/10.1172/jci.insight.138999.

63. Zuo Y, Zuo M, Yalavarthi S, Gockman K, Madison JA, Shi H, et al. Neutrophil extracellular traps and thrombosis in COVID-19. J Thromb Thrombolysis. 2021;51(2):446-53. https://doi.org/10. 1007/s11239-020-02324-z.

64. Gould TJ, Vu TT, Swystun LL, Dwivedi DJ, Mai SH, Weitz JI, et al. Neutrophil extracellular traps promote thrombin generation through platelet-dependent and platelet-independent mechanisms. Arterioscler Thromb Vasc Biol. 2014;34(9):1977-84. https://doi. org/10.1161/ATVBAHA.114.304114.

65. Kambas K, Chrysanthopoulou A, Vassilopoulos D, Apostolidou E, Skendros P, Girod A, et al. Tissue factor expression in neutrophil extracellular traps and neutrophil derived microparticles in antineutrophil cytoplasmic antibody associated vasculitis may promote thromboinflammation and the thrombophilic state associated with the disease. Ann Rheum Dis. 2014;73(10):1854-63. https://doi.org/10.1136/annrheumdis-2013-203430.

66. Jimenez-Alcazar M, Rangaswamy C, Panda R, Bitterling J, Simsek YJ, Long AT, et al. Host DNases prevent vascular occlusion by neutrophil extracellular traps. Science. 2017;358(6367):12026. https://doi.org/10.1126/science.aam8897.

67. Ma AC, Kubes P. Platelets, neutrophils, and neutrophil extracellular traps (NETs) in sepsis. J Thromb Haemost. 2008;6(3):415-20. https://doi.org/10.1111/j.1538-7836.2007.02865.x.

68. Ed Rainger G, Chimen M, Harrison MJ, Yates CM, Harrison P, Watson SP, et al. The role of platelets in the recruitment of leukocytes during vascular disease. Platelets. 2015;26(6):507-20. https://doi.org/10.3109/09537104.2015.1064881.

69. Smyth SS, McEver RP, Weyrich AS, Morrell CN, Hoffman MR, Arepally GM, et al. Platelet functions beyond hemostasis. J Thromb Haemost. 2009;7(11):1759-66. https://doi.org/10.1111/j. 1538-7836.2009.03586.x.

70. Loo J, Spittle DA, Newnham M. COVID-19, immunothrombosis and venous thromboembolism: biological mechanisms. Thorax. 2021. https://doi.org/10.1136/thoraxjnl-2020-216243.

71. Handtke S, Thiele T. Large and small platelets-(when) do they differ? J Thromb Haemost. 2020;18(6):1256-67. https://doi.org/ $10.1111 /$ jth.14788.

72. Zhang S, Liu Y, Wang X, Yang L, Li H, Wang Y, et al. SARSCoV-2 binds platelet ACE2 to enhance thrombosis in COVID19. J Hematol Oncol. 2020;13(1):120. https://doi.org/10.1186/ s13045-020-00954-7.

73. Hottz ED, Azevedo-Quintanilha IG, Palhinha L, Teixeira L, Barreto EA, Pao CRR, et al. Platelet activation and platelet-monocyte aggregate formation trigger tissue factor expression in patients with severe COVID-19. Blood. 2020;136(11):1330-41. https:// doi.org/10.1182/blood.2020007252.
74. Manne BK, Denorme F, Middleton EA, Portier I, Rowley JW, Stubben C, et al. Platelet gene expression and function in patients with COVID-19. Blood. 2020;136(11):1317-29. https://doi.org/ 10.1182/blood.2020007214.

75. Zhang D, Guo R, Lei L, Liu H, Wang Y, Wang Y, et al. Frontline science: COVID-19 infection induces readily detectable morphologic and inflammation-related phenotypic changes in peripheral blood monocytes. J Leukoc Biol. 2021;109(1):13-22. https://doi. org/10.1002/JLB.4HI0720-470R.

76. Aggarwal M, Dass J, Mahapatra M. Hemostatic abnormalities in COVID-19: an update. Indian J Hematol Blood Transfus. 2020;36(4):1-11. https://doi.org/10.1007/s12288-020-01328-2.

77. Zhou Y, Fu B, Zheng X, Wang D, Zhao C, Qi Y, et al. Pathogenic T-cells and inflammatory monocytes incite inflammatory storms in severe COVID-19 patients. Natl Sci Rev. 2020;7(6):998-1002. https://doi.org/10.1093/nsr/nwaa041.

78. Perlman S, Dandekar AA. Immunopathogenesis of coronavirus infections: implications for SARS. Nat Rev Immunol. 2005;5(12):917-27. https://doi.org/10.1038/nri1732.

79. Magro C, Mulvey JJ, Berlin D, Nuovo G, Salvatore S, Harp J, et al. Complement associated microvascular injury and thrombosis in the pathogenesis of severe COVID-19 infection: a report of five cases. Transl Res. 2020;220:1-13. https://doi.org/10.1016/j.trsl. 2020.04.007.

80. Noris M, Benigni A, Remuzzi G. The case of complement activation in COVID-19 multiorgan impact. Kidney Int. 2020;98(2):314-22. https://doi.org/10.1016/j.kint.2020.05.013.

81. Eriksson O, Hultstrom M, Persson B, Lipcsey M, Ekdahl KN, Nilsson B, et al. Mannose-binding lectin is associated with thrombosis and coagulopathy in critically ill COVID-19 patients. Thromb Haemost. 2020;120(12):1720-4. https://doi.org/10.1055/ s-0040-1715835.

82. Wojta J, Kaun C, Zorn G, Ghannadan M, Hauswirth AW, Sperr $\mathrm{WR}$, et al. C5a stimulates production of plasminogen activator inhibitor-1 in human mast cells and basophils. Blood. 2002;100(2):517-23. https://doi.org/10.1182/blood.v100.2.517.

83. Lupu F, Keshari RS, Lambris JD, Coggeshall KM. Crosstalk between the coagulation and complement systems in sepsis. Thromb Res. 2014;133(Suppl 1):S28-31. https://doi.org/10. 1016/j.thromres.2014.03.014.

84. Wan S, Yi Q, Fan S, Lv J, Zhang X, Guo L, et al. Characteristics of lymphocyte subsets and cytokines in peripheral blood of 123 hospitalized patients with 2019 novel coronavirus pneumonia (NCP). medRxiv. 2020;2020(02):10.20021832. https://doi.org/ 10.1101/2020.02.10.20021832.

85. Chau AS, Weber AG, Maria NI, Narain S, Liu A, Hajizadeh $\mathrm{N}$, et al. The longitudinal immune response to coronavirus disease 2019: chasing the cytokine storm. Arthritis Rheumatol. 2021;73(1):23-35. https://doi.org/10.1002/art.41526.

86. Wu D, Yang XO. TH17 responses in cytokine storm of COVID19: an emerging target of JAK2 inhibitor fedratinib. J Microbiol Immunol Infect. 2020;53(3):368-70. https://doi.org/10.1016/j. jmii.2020.03.005

87. Diao B, Wang C, Tan Y, Chen X, Liu Y, Ning L, et al. Reduction and functional exhaustion of T cells in patients with coronavirus disease 2019 (COVID-19). Front Immunol. 2020;11:827. https:// doi.org/10.3389/fimmu.2020.00827.

88. Kruse JM, Magomedov A, Kurreck A, Munch FH, Koerner R, Kamhieh-Milz J, et al. Thromboembolic complications in critically ill COVID-19 patients are associated with impaired fibrinolysis. Crit Care. 2020;24(1):676. https://doi.org/10.1186/ s13054-020-03401-8.

89. Uthman IW, Gharavi AE. Viral infections and antiphospholipid antibodies. Semin Arthritis Rheum. 2002;31(4):256-63. https:// doi.org/10.1053/sarh.2002.28303. 
90. Shoenfeld Y, Blank M, Cervera R, Font J, Raschi E, Meroni PL. Infectious origin of the antiphospholipid syndrome. Ann Rheum Dis. 2006;65(1):2-6. https://doi.org/10.1136/ard.2005.045443.

91. Bowles L, Platton S, Yartey N, Dave M, Lee K, Hart DP, et al. Lupus anticoagulant and abnormal coagulation tests in patients with Covid-19. N Engl J Med. 2020;383(3):288-90. https://doi. org/10.1056/NEJMc2013656.

92. Zhang Y, Cao W, Jiang W, Xiao M, Li Y, Tang N, et al. Profile of natural anticoagulant, coagulant factor and anti-phospholipid antibody in critically ill COVID-19 patients. J Thromb Thrombolysis. 2020;50(3):580-6. https://doi.org/10.1007/s11239-020-02182-9.

93. Zuo Y, Estes SK, Ali RA, Gandhi AA, Yalavarthi S, Shi H, et al. Prothrombotic autoantibodies in serum from patients hospitalized with COVID-19. Sci Transl Med. 2020;12(570):eabd3876. https:// doi.org/10.1126/scitranslmed.abd3876.

94. Connors JM, Brooks MM, Sciurba FC, Krishnan JA, Bledsoe JR, Kindzelski A, et al. Effect of antithrombotic therapy on clinical outcomes in outpatients with clinically stable symptomatic COVID-19: the ACTIV-4B randomized clinical trial. JAMA. 2021. https://doi.org/10.1001/jama.2021.17272.

95. Sholzberg M, Tang GH, Rahhal H, AlHamzah M, Kreuziger LB, Ainle FN, et al. Effectiveness of therapeutic heparin versus prophylactic heparin on death, mechanical ventilation, or intensive care unit admission in moderately ill patients with covid- 19 admitted to hospital: RAPID randomised clinical trial. BMJ. 2021;375: n2400. https://doi.org/10.1136/bmj.n2400.
96. Investigators A, Investigators AC-a, Investigators R-C, Lawler PR, Goligher EC, Berger JS, et al. Therapeutic anticoagulation with heparin in noncritically ill patients with Covid-19. N Engl J Med. 2021;385(9):790-802. https://doi.org/10.1056/NEJMoa2105911.

97. Investigators I, Sadeghipour P, Talasaz AH, Rashidi F, SharifKashani B, Beigmohammadi MT, et al. Effect of intermediatedose vs standard-dose prophylactic anticoagulation on thrombotic events, extracorporeal membrane oxygenation treatment, or mortality among patients with COVID-19 admitted to the intensive care unit: the INSPIRATION randomized clinical trial. JAMA. 2021;325(16):1620-30. https://doi.org/10.1001/jama.2021.4152.

98. Spyropoulos AC, Goldin M, Giannis D, Diab W, Wang J, Khanijo $\mathrm{S}$, et al. Efficacy and safety of therapeutic-dose heparin vs standard prophylactic or intermediate-dose heparins for thromboprophylaxis in high-risk hospitalized patients with COVID-19: the HEP-COVID randomized clinical trial. JAMA Intern Med. 2021. https://doi.org/10.1001/jamainternmed.2021.6203.

Publisher's note Springer Nature remains neutral with regard to jurisdictional claims in published maps and institutional affiliations. 